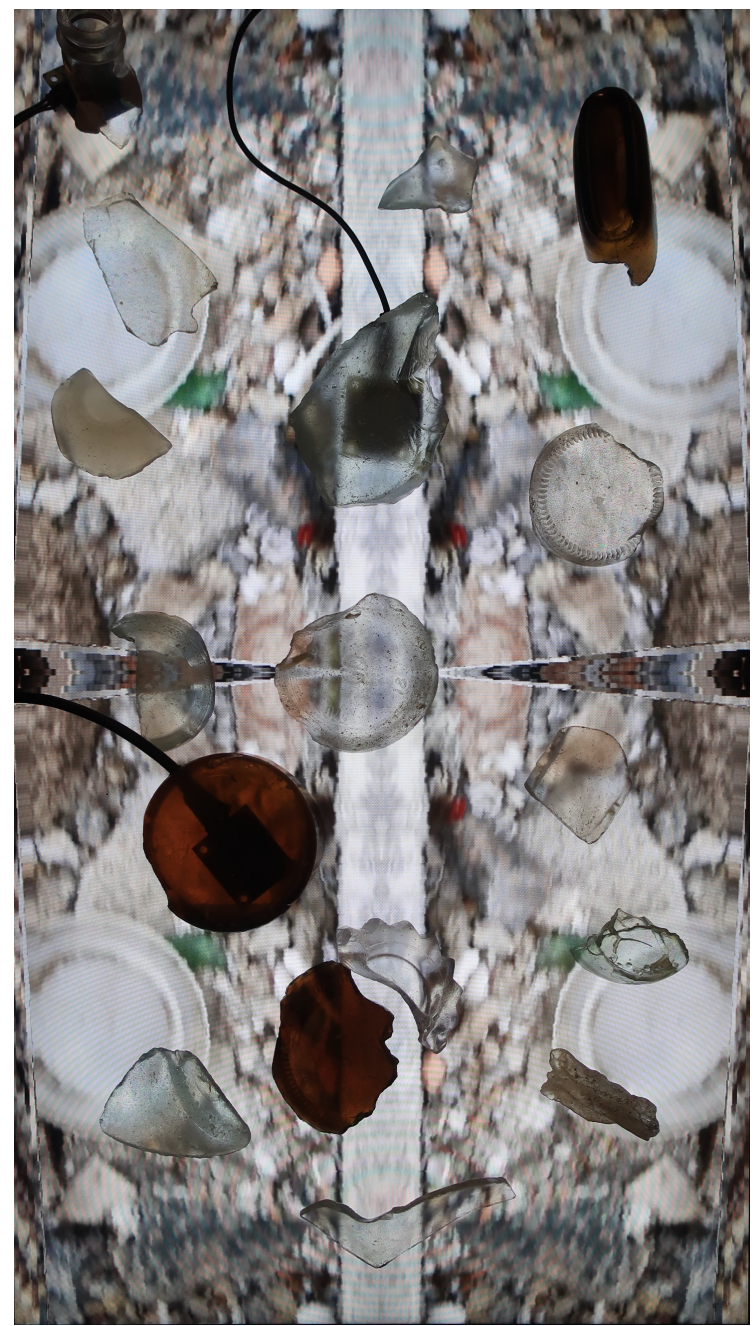

Figure 1: Top view of the Lamma Glass interactive video installation with tangible objects, embedded sensors and screen.

\section{Tangible Landscapes and Abstract Narratives}

\section{Bert Bongers}

Faculty of Transdisciplinary Innovation

Faculty of Design, Architecture and Building

University of Technology Sydney

bert.bongers@uts.edu.au

\section{ABSTRACT}

The Tangible Landscapes range of interactive audiovisual and sculptural pieces offer audiences opportunities to explore abstract landscapes, recreating an embodied experience of the materials, through tangible interaction with found objects. The objects can contain sensors (tilt, orientation, movement, proximity, pressure, etc) which allow the audience to manipulate the video material through the sensors influencing the algorithms in the system. New meanings and new narratives can emerge from the audience interactions, explorations and interpretations, combining the individual and social, as well as the intimate and the spatial. Interactive art in general, and these pieces in particular, encourage and support the audience to create their own unique experiences, allowing for an individual sense of agency. The resulting patterns and images that emerge from the interaction, though these deliberate opportunities, a participative process of co-creating.

This paper presents a range of these Tangible Landscape pieces, their relationship with earlier pieces and research, and placed in a context of artistic expression engaging with nature such as Landscape Art.

KEYWORDS Tangible Interactive Art; Embodiment; Materiality; Video

Permission to make digital or hard copies of part or all of this work for personal or classroom use is granted without fee provided that copies are not made or distributed for profit or commercial advantage and that copies bear this notice and the full citation on the first page. Copyrights for third-party components of this work must be honored. For all other uses, contact the owner/author(s).

TEI'20 Extended Abstracts, February 9-12, 2020, Sydney, Australia.

(C) 2020 Copyright is held by the author/owner(s).

ACM ISBN 978-1-4503-6107-1/20/02. DOI: https://doi.org/10.1145/3374920.3375292 


\section{BACKGROUND}

There are many ways to translate and transform landscapes and other environments (natural and/or human-made) into an installation or gallery experience. Tangible Landscapes is a range of interactive, audiovisual installations that aim to provide the visitor with tangible connections with a remote landscape, as a new experience of the body and space locally.

The pieces usually start from encounters with found objects or situations, that elicit a certain fascination and unusual presence. This can be a particular selection of glass objects on a beach, deserted bunkers covered in the most colourful graffiti, interestingly shaped driftwood, rocks,

lichen, but also particular juxtapositions, patterns and forms, etc. Rather than attempting a literal translation, a more poetic, metaphorical, embodied and extended experience is sought. Video, audio and physical objects are captured and collected, which form the basis of the work developed. The physical objects are decontextualized, and then re-contextualised in the works. By combining the found objects with sensors, their potential for reaching out is extended, from their usually passive by-stander role in the original context, to catalysts and even active participants in the interactive work. Objects are usually selected based on their tangible qualities, for aesthetics of touch and handling, but also for the potential stories they can tell. Driftwood for example, embodies a past life as part of a tree, often very ancient, and then a further 'life' being shaped and influenced by the sea and other elements, developing a narrative of which it has been an integral part as witness, and as bearer of experiences.

Video recording is used to capture patterns, shapes and environments, and in order to form a suitable basis for an interactive display usually a high framerate is used (240fps), so that it becomes possible for the audience to zoom in in time, and high resolution for zooming in in space, but often also lower resolutions are suitable when the work is collaged.

Several recipes for translations and trans(inter)actions are possible. Sounds are often performed on site and captured, in addition to the resident soundscape of a location. This requires further physical interaction with a situation, taking advantage of the sonic potentials of objects that can be rhythmically or melodically explored. Again, the aim of this material is that it is manipulable, through zooming in, time stretching, spatialising, filtering etc.

The experience of the body in the source environment, is largely moved to the background, and replaced with a new potential for embodiment, of the audience's body in the new interactive, tangible and audiovisual environment.

\section{RELATED WORK}

To place the Interactive Landscape works presented here in an artistic and historical context, below a short exploration of related artistic expressions is presented. Traditionally, art at a landscape scale and context is well known in Land and Environmental Art [14] and is certainly an inspiration. Further related work can be found in other interactive video art works that use images and patterns of nature. There are very few examples of the use of new media and interactive technology in nature, 


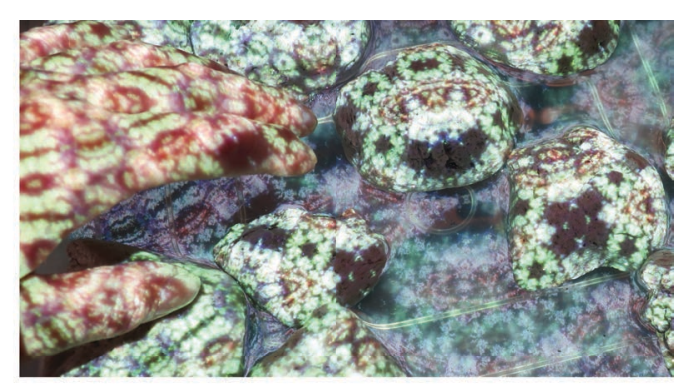

rigure 4: rumice rioating, witn interactive video projection

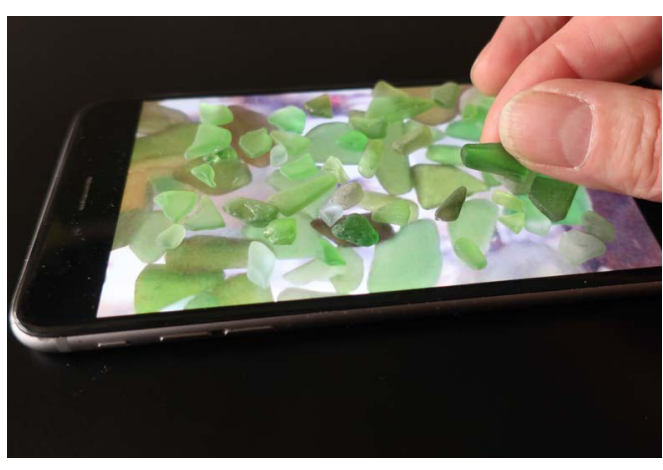

Figure 5: Miniature Tangible Landscape piece, shards of green glass from Malabar Beach which was the reason for organising a workshop at the Australian $\mathrm{HCl}$ conference $\mathrm{OzCHI}$ in 2011 , Rural $\mathrm{HCl}$ - distributed interaction on a landscape scale [6].

\section{Landscape Art}

For decades, artists like Richard Long, Andy Goldsworthy, James Turrell [17], David Nash and Antony Gormley have engaged with artistic expression on a landscape scale, interacting between the natural and artificial environment. It is interesting to see what strategies they have used, to relate the landscape interactions to the gallery or museum. Richard Long often undertakes walks in landscapes and documents the traces he makes in photographs and stories, presented to the public. But Long also often collects objects such as rocks and sticks, and re-situates these in a museum context, creating patterns and sculptures out of these found objects [15]. Antony Gormley's outdoor sculptures made of steel engage with the landscape, conceptually but also physically, the rusting of the iron reflects the interaction with the environment, an ever developing patina [12]. The same process can be seen in the site-specific monumental scale sculptures of Richard Serra, and those of Eduardo Chilida.

Andy Goldsworthy often works in nature, creating sculptures and structures in situ, out of objects encountered in nature (sticks, rocks, pieces of slate, ice). These structures are often deliberately instable, and dynamic, using streams, tides, wind, melting snow, and other elements. I used to think that the beautiful photos presented in glossy books [11] were a bit too polished, but the documentary Rivers and Tides shows an immense dedication to working in harmony with nature, and through what lengths of trouble and hardship Goldsworthy goes in order to create the pieces [19]. The struggle and search for balance is an integral part of his art works. We can also see in this work the intention to create dynamic, in some sense interactive sculptures, for instance a large sculpture made out of pieces of slate, first the race against the incoming tide to finish it, and then the dissolving of the structure.

David Nash takes this notion even further, famously using a chain saw to create his wooden sculptures, in such a way that the shapes develop over time, 'warp and crack'. Nash's ambition was to become fluent with the material, "to learn to 'speak' wood", allowing the material to lead, and not treat it as dumb and inert [18, p41]. He also often uses charring as a technique to change shape and appearance of wood sculptures. Even slower timescale of interaction is shown in his 'growing works', since the late 1970s, through planting and pruning trees, taking decades to take shape. The oldest started in 1977, Ash Dome in Wales, which is a circle of ash trees planted in a circle, and through pruning eventually forming a dome shape. Another 'growing work' that I engaged with myself is Divided Oaks, which Nash planted in 1984 (and maintained since) in The Netherlands, in the national park De Hoge Veluwe, near the Kröller-Müller museum and sculpture park [18, p59]. I wasn't aware of the presence of the work when I cycled past in the Autumn of 2018, but it was immediately apparent as human-influenced nature, and recognised it as a work by David Nash. In Divided Oaks, the trees were forced to grow ("lean") in either West or East direction, creating an interesting and meaningful pattern. Nash has sometimes been criticised for manipulating trees, but pruning and shaping trees and shrubs has been done for centuries, often 


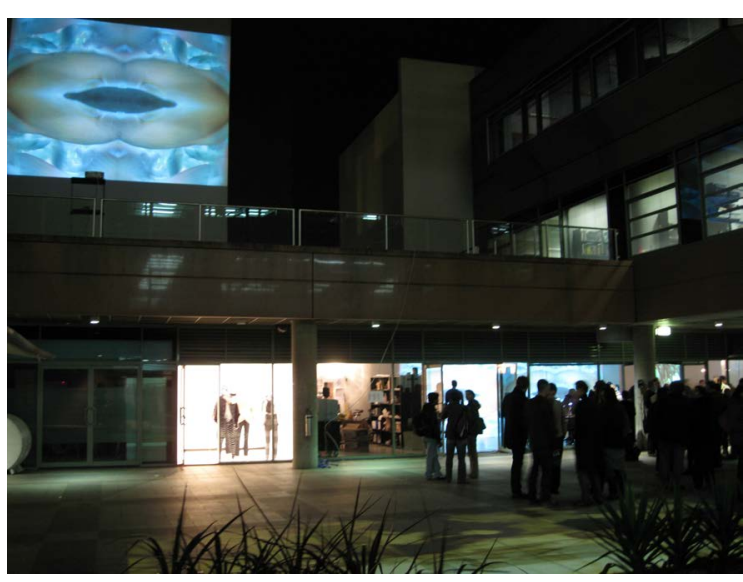

Figure 6: Facets projection (indoors as well as outdoors) during the Interactivation Studio opening, 2008.

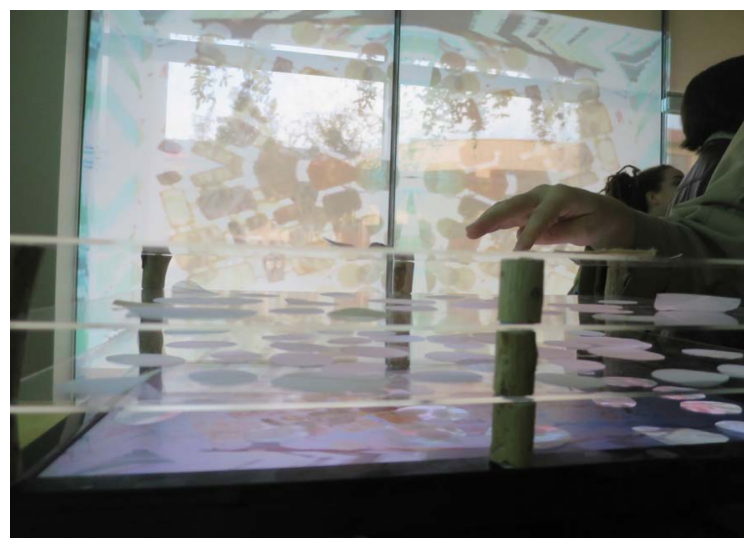

Figure 7: Pattern Station \#2 installation during TEI 2015 for practical but also for ornamental purposes. In an interview in the catalogue of his exhibition in the Tate St. Ives in 2004, he was asked about this "pure torture for the tree" [8]. Nash explains in his answer that "man has influenced the natural and living environment for centuries in similar or far more brutal ways", and as he puts it elsewhere "there is a sense that it's OK for hedges but not for art" [18, p48]. This of course ties in with a broader discussion on human influence on the environment, including the topic of the dangers of climate change and the wider context of the Anthropocene - how we, as a species, have been so 'successful' in exploiting nature that we actually doomed the future of the natural environment (including ourselves) with exponentially increasing extinction of species and other irreversible damage. Instead of this exploitation for short term profit (through mining, large scale industrialised agriculture, land clearing in rainforests etc), a holistic approach is more appropriate. For instance in the traditional Australian aboriginal culture, who see themselves as the custodians of the land with an emphasis on regeneration and maintenance. For example, the use of 'firestick farming' had effectively shaped the whole continent into a healthy environment which contributed to the avoidance of out-of-control raging bushfires, which are common since Western colonisation [10] [9, pp217-236]. As David Nash observes, "Forests are healthier for some extraction of trees but suffer grievously if there is over extraction" [18, p48]. Probably the best example of a 'landscape narrative' is David Nash's work Wooden Boulder, which travelled through the Welsh landscape over the course of 25 years, mostly by forces of nature. The work started in 1978 when Nash cut a sphere of $1.5 \mathrm{~m}$ diameter (owing to "having acquired a larger chainsaw") out of a large oak tree, which was felled after it got uprooted by a storm. The boulder was put in the stream initially as a way to get the wood down to his studio, but it became an actor in a landscape narrative, and with little intervention along the way made its way down the stream, owing to seasonal flooding, storms, a tidal estuary, floodplains, and eventually disappearing out to sea in 2003 [18, pp 66-75].

\section{Interactive and Media Art and landscape}

Interactive video environments are often created with direct references to nature, such as the works by the Japanese collective teamLab, which use computer generated imagery of flowers and birds [20]. Daan Roosegaarde's work Dune, in various incarnations since 2007 (it was in the Biennale of Sydney in 2012), may seem a high-tech emulation of waving reeds (made out of fibreglass, and interactive lights on the top), but actually fascinates in its elaborate sonic and light responses to audiences touching and waving around it, seemingly coming alive.

Many of the works of Olafur Eliasson involve references to nature, bringing in dynamic elements and materials, using light, water, vapour, reflections, and movement [13].

The works of Rafael Lozano-Hemmer are always very playful yet sophisticated, engaging audiences in bodily and tangible ways, and some are in a monumental scale using projections. His work Pulse Room takes individual audience members heartbeat, displayed in a single pulsing incandescent light bulb among a room full of pulsating light bulbs reminiscing the heartbeats of past visitors. The work was initially developed in 2006, and I have experienced a version of it in his solo exhibition at the Museum of Contemporary Art in Sydney in 2012 [16, pp38-42] and another 


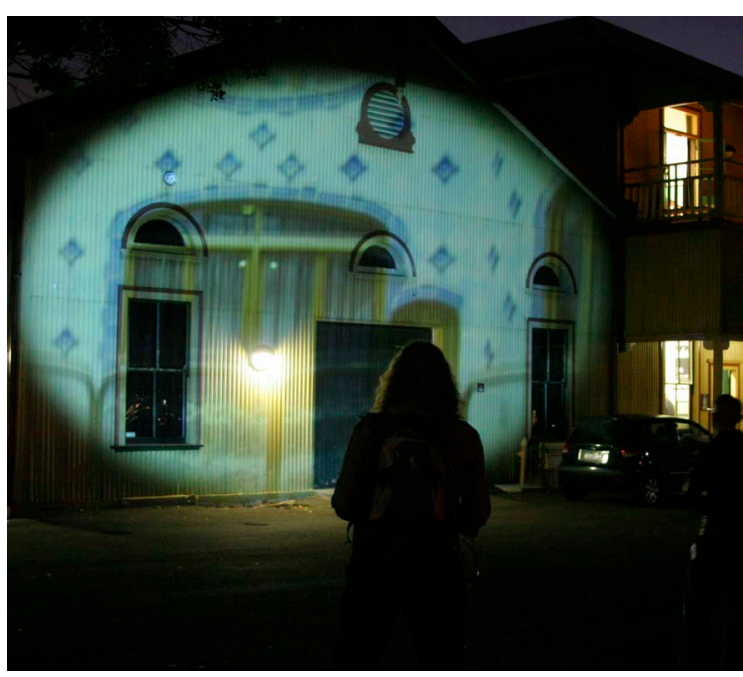

Figure 8: Videowalker projection in urban environment (2009 performance in SEAM festival)

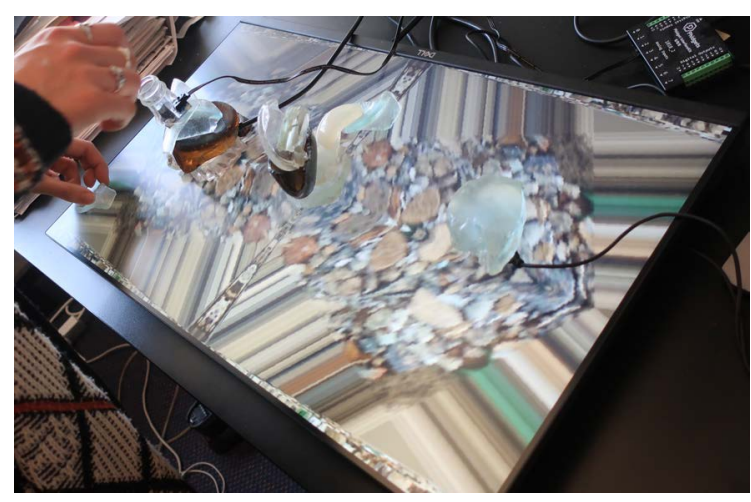

Figure 9: Objects stacked in Lamma Glass installation one at the Museum of Old and New Art (MONA) in Hobart in 2011. In a landscape scale version of the work, Pulse Park in 2008, pulsating stage lights were used creating dynamic beams across the grass of a lawn (albeit in an urban environment) [16, p26].

\section{EARLIER WORK AND INSPIRATION}

My previous interactive video environments were often been engaged with creating patterns, and explicit in its aim to offer the audience to co-create experiences. This is done through using collages and live projections [3], such as the Facets range of interactive projections which video source material is mostly derived from nature.

Recent work explored materiality, in collaboration with textile artist Cecilia Heffer, fusing lace patterns with video patterns, linked through sensors and interactivity, presented at several exhibitions including the TEI 2015 conference at Stanford University [4].

With this new range of pieces of Tangible Landscapes the aim is to create more intimate and tangible experiences, still allowing the audience to create their own versions of the work, reaching out to landscapes through the material and interactivity offered. The audience can explore and interpret the materials, find new meanings and narratives in addition to the existing ones. and perhaps finding completely new experiences. These pieces are not prescriptive.

The pieces also derive inspiration from my earlier experiences as electronic musical instrument designer and builder, since the late 1980s at STEIM in Amsterdam and Sonology in The Hague, and various collaborators (composers, musicians, dancers) around the world [2]. I approach video in the same way as I approach sonic material, aiming to create visual musical instruments [1].

Many people have used video projections in urban but also in natural environments, my first experiments were in 2000 and developed a portable projection instrument since 2003 (with a backpack containing a battery, converter, speaker, and laptop computer running the video software, and a strong projector fitted with sensors controlling parameters of the audiovisual material in real time) [5]. Projector performances ('video-walks') have taken place in galleries and urban environments, but also in nature, projecting on trees, water, cliffs, and in caves.

\section{TANGIBLE LANDSCAPE INSTALLATIONS - STRUCTURE}

Each piece consists of a screen, usually placed vertically, ranging in size from 17" to 32", on which objects are placed which a related to the source of the video material. The objects can contain sensors, which manipulate and influence the audiovisual material. Further sensing is done through RFID tags in the objects, and RFID readers around the screen, and around the pieces there are spatial sensors detecting the audience presence, deliberate, explicit and implicit movements. In some instances a camera is integrated in the setup.. This mixes a live-feed of the manipulation of the objects into the pre-recorded video material, which also allows for video-feedback loops, as used in earlier pieces. The sensors in the video are usually wired (USB) (also to prevent theft), when needed wireless sensor nodes are used. The audiovisual material is interactively played by a computer (Apple $\mathrm{Mac}$ ) running a Max/MSP/Jitter patch that creates the manipulations in real-time (rotation, zoom, 


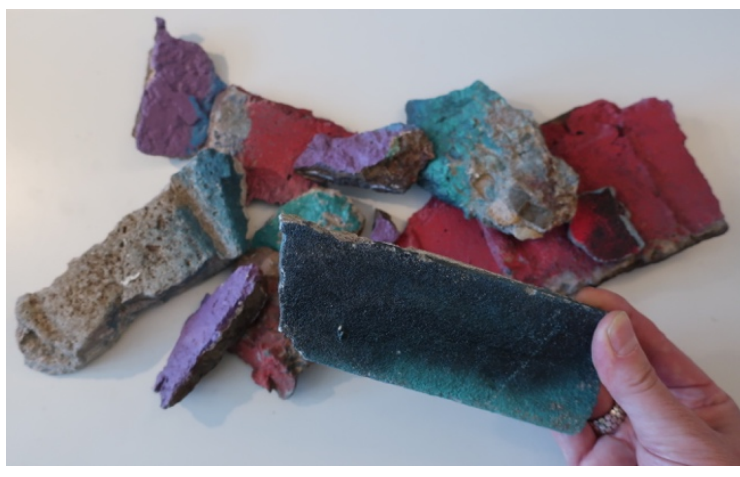

Figure 10: Pieces of graffiti-coloured concrete from Malabar area stretch, speed, etc.). There is a large range of parameters, which can be controlled by the sensors. Furthermore, certain behaviours are programmed into the system, making the responses less deterministic, but not random: the responses can be based on earlier interactions, creating ongoing variations in experiences, in addition to the richness emerging from the real-time parameters of the sensors. All sensors integrated in the objects are continuous (analogue-to-digital, high resolution and sample rate for real-time interaction), not triggers, allowing for really playing with the material.

The Max patch also allows for recording data of interactions (anonymous of course), for further analysis and interpretation.

\section{LAMMA GLASS}

The piece shown in the images (Fig. 1, 2,9) is based on material gathered on a beach on Lamma Island in Hong Kong (in February 2019). The shards of glass are unusually thick, and also different shapes of what I usually find on beaches on Sydney harbour (such as the glass bottle bottoms shown in Figure 3, one of the other pieces). Two videos were captured, one of dry patterns and (glass) objects, another one with a thin layer of sea over the objects. The glass pieces were collected afterwards. Due to their weight, they have the right 'feel' for manipulating video motions (rotations and zooming), as found in earlier pieces, where we used wooden blocks of about $100 \mathrm{~g}$ or even a rock of over 200g. (The attached accelerometers are used for tilt sensing in two axes on the horizontal plane, and can be further extended with compass and gyroscope signals, mapped to further video manipulations.).

A first version of the piece was informally presented during a public talk near the end of my one month teaching \& research residency, at the Hong Kong Polytechnic University School of Design. In that version a video-feedback loop was used, using a mirror and overhead camera, and some sensors. The current version extends the interaction with more parameters and behaviours.

As an example of the potential for individual interpretation, one test person started to explore the possibilities of the objects by stacking them up, as shown in Fig. 9. This kind of unanticipated behaviour is precisely what shows the potential for emergence of individual experiences. The aim of these works is to invite the audience to co-create the experience.

\section{OTHER PIECES AND FURTHER WORK}

A range of pieces are being developed, in various stages of completion, using a rich variety of materials and locations, and different modes of interaction, and scales of presentation from the miniature to larger scale projections. Some of the image manipulations and objects are shown in Figures 3, 4, 5, 10 and 11.

The pumice rocks are a particularly interesting landscape narrative. They were found early in 2014, when exceptionally large pieces washed up on several Sydney beaches, many the size of a fist. The pumice originated from an underwater volcanic eruption (of the Havre Seamount, near the Kermadec Islands, about $1000 \mathrm{~km}$ north east of New Zealand) in July 2012. The rocks were collected 
with the intention to create a floating projection surface. A test setup is shown in Figure 4, the rocks are floating in a basin, on top of a video screen, and a video projection from above.

The exhibition will be used to gather data and make further observations of audience interactions with the pieces and the materials, and explore new possibilities.

There are also some larger materials, pieces of driftwood, possibly more suited for larger scale installations using projections.

\section{CONCLUSION}

The Tangible Landscapes pieces offer the audience opportunities to explore the re-embodiment of a remote landscape, translated and transformed through their explorations and interactions of the objects, sensors, and audiovisual materials, all interrelated and accessible. New and personal interpretations are possible. The pieces allow for new narratives and experiences to emerge, from the intimate to the spatial, and from the individual to the shared and social interactions.

These installations also encourage audiences to reflect on the relationship between technology and the natural environment, potentially meditating on the need for respect and appreciation of nature. It is the intention to emphasise that there can be a harmonious relationship between the natural and the artificial, that digital technology can mix and merge with it and is not restricted to urban environments.
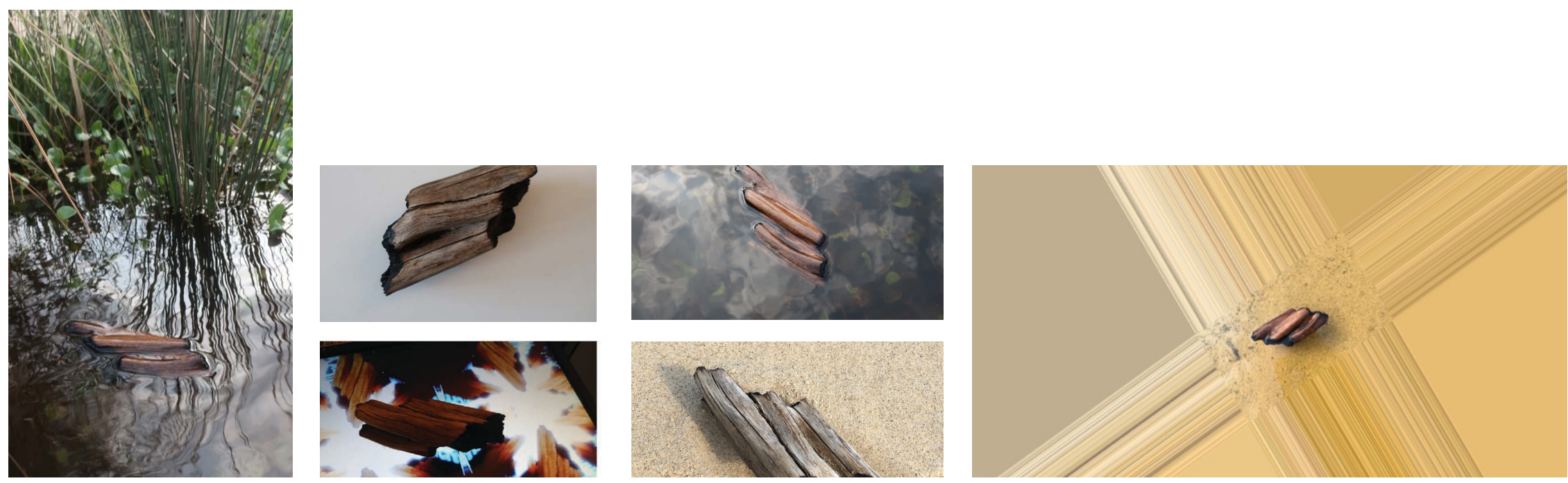

Figure 11: Driftwood object floating, in various contexts, and interactive video manipulation patterns 


\section{REFERENCES}

[1] Bongers, A.J. and Harris, Y.C., A Structured Instrument Design Approach: The Video-Organ. In: Proceedings of the Conference on New Instruments for Musical Expression (NIME), Dublin Ireland, 2002

[2] Bongers, A. J., Electronic Musical Instruments: Experiences of a New Luthier, Leonardo Music fournal, Vol. 17, pp. 9-16. 2007

[3] Bongers, A. J., Interactive Video Projections as Augmented Environments, International fournal of Arts and Technology, 15/1, pp17 - 52, 2012

4] Bongers, A. J. and Heffer, C., Pattern Stations - Extending Textile Materials through Tangible Interaction. In: Proceedings of the International Conference on Tangible, Embedded and Embodied Interaction (TEI), pp 405 - 406, ACM, Stanford January 15 - 19, 2015

[5] Bongers, A. J., The Projector as Instrument, fournal of Personal and Ubiquitous Computing, Special Issue on Personal Projection, 16/1, pp65-75, 2011

[6] Bongers, A. J. (Ed.) Rural HCI - distributed interaction on a landscape scale. Workshop at the $\mathrm{OzCHI}$ Conference, Canberra Australia, 2011 http://www.educ.dab.uts.edu.au/interactivation/RuralHCI/

[7] Chong, A. and Rijk, T. de., Daan Roosegaarde - interactive landscapes. NAi Publishers, 2010

[8] Daniel-McElroy, S., Interview with David Nash. Published for the exposition David Nash, Making and Placing, abstract sculpture 1978 - 2004. Tate St Ives, Cornwall 2004

[9] Flannery, T. F. The Future Eaters - an ecological history of the Australasian lands and people. Reed New Holland, 1994

[10] Gammage, B., The Biggest Estate on Earth - how Aborigines made Australia. Allen \& Unwin, 2011

[11] Goldsworthy, A., Andy Goldsworthy - projects. Abrams, 2017

[12] Gormley, A. (Ed.), Inside Australia, Thames \& Hudson, 2005

13] Grynsztejn, M. (Ed.), Take Your Time - Olafur Eliasson. Thames \& Hudson, 2007

[14] Kastner, J. and Wallis, B. Land and Environmental Art. Phaidon, 1998

[15] Long, R., Richard Long - walking the line. Thames \& Hudson, 2002

[16] Lozano Hemmer, R., Recorders. Manchester Art Gallery, 2010

[17] Molony, J. and McKendry, M., James Turrell - a retrospective. Catalogue of the exhibition 13/12/2014 28/6/2015, National Gallery of Australia, Canberra. 2014

[18] Nash, D., David Nash, Thames \& Hudson, 2007

[19] Riedelsheimer, T., Rivers and Tides. 2001

[20] teamLab, teamLab 2001-2016. Koumeisha Inc., 2016 